This item was submitted to Loughborough's Research Repository by the author.

Items in Figshare are protected by copyright, with all rights reserved, unless otherwise indicated.

\title{
Uncertainty perception in bidding for Product-Service Systems under competition
}

PLEASE CITE THE PUBLISHED VERSION

https://doi.org/10.1016/j.pursup.2017.10.003

PUBLISHER

(C) Elsevier

VERSION

AM (Accepted Manuscript)

\section{PUBLISHER STATEMENT}

This work is made available according to the conditions of the Creative Commons Attribution-NonCommercialNoDerivatives 4.0 International (CC BY-NC-ND 4.0) licence. Full details of this licence are available at: https://creativecommons.org/licenses/by-nc-nd/4.0/

\section{LICENCE}

CC BY-NC-ND 4.0

\section{REPOSITORY RECORD}

Kreye, Melanie E., Yee Goh, and Linda B. Newnes. 2017. "Uncertainty Perception in Bidding for Productservice Systems Under Competition”. figshare. https://hdl.handle.net/2134/23202. 


\section{Uncertainty in bidding for Product-Service Systems: The influence of competition on decision making}

Melanie E. Kreye ${ }^{1 *}$, Yee Mey Goh ${ }^{2,}$ Linda B. Newnes ${ }^{3}$

1) Department of Management Engineering, Technical University of Denmark, Kgs. Lyngby, Denmark

2) Wolfson School of Mechanical and Manufacturing Engineering, Loughborough

University, Loughborough, UK

3) Department of Mechanical Engineering, University of Bath, Bath, UK

* Corresponding author. Mail: DTU, Department of Management Engineering,

Produktionstorvet 424, 2800 Kgs. Lyngby, Denmark. Email: mkreye@dtu.uk. 


\title{
Uncertainty in bidding for Product-Service Systems: The influence of competition on decision making
}

\author{
Abstract: \\ This research investigates what impact the existence of competition has on the \\ pricing decision for Product-Service Systems (PSS) under uncertainty. PSS \\ provision is an increasingly important area for many businesses and competition \\ increases cognitive pressures on providers even further. We present an empirical \\ study with industrial experts from the defence and aerospace sector, in cost \\ estimation and bidding. The study consisted of an experimental set-up via two \\ questionnaires which differed in the existence of competition in the bidding \\ scenario. The findings showed that bidding decision makers changed their \\ evaluation of the cost estimate due to the introduction of competition but kept \\ their evaluations of the profit margin and price bids constant. Furthermore, the \\ participants listed the relevant sources of uncertainty that influenced their \\ decision-making process. This research contributes to the literature in two ways. \\ First, our findings showed that predictions from current theory regarding \\ decision-making of cost estimation and pricing are not confirmed when \\ competitively bidding for PSS. Second, we show uncertainty sources that \\ influenced the decision makers and identified $p$ the importance of internal \\ processes of the PSS provider and environmental uncertainty.
}

Keywords: uncertainty; competitive bidding; decision making; Product-service systems; service contracts; information 


\section{Introduction}

Manufacturing companies increasingly adopt a servitization strategy, where services and products are integrated into Product-Service Systems (PSS) to add value for the customer (Vandermerwe and Rada 1988, Hawkins et al. 2015, Lacoste and Johnsen 2015). Examples are the ten year engine support contract for the Eurofighter Typhoon which is valued at $£ 865$ million (Defense Industry Daily 2011) and the Australian Anzac Support Contract where military surface ships will be serviced for an initial period of five years (Babcock 2012). PSS offer many advantages for providers such as increased profits, stability in cash flow and increased customer demand through lock-in situations (Wise and Baumgartner 1999). However, in practice, many of these advantages are not realised as only $21 \%$ of companies succeed with their PSS business (Baveja et al. 2004). In line with these observations, Rapaccini (2015) reports that PSS providers frequently under-price their offerings and overpromise regarding their performance because of the operational novelty and complexity of PSS for their business. Thus, many servitized manufacturers fail to make suitable pricing decisions for their PSS offerings.

PSS contracts are typically allocated through competitive bidding against other leading suppliers in the market (Kleemann and Essig 2013, Kreye et al. 2013) which creates various challenges for the provider's decision maker in determining a suitable price bid. On the one hand, decision makers may be encouraged to set a high price value because of the high operational uncertainty of PSS to ensure future profitability (Benedettini et al. 2015). On the other hand, the existence of competition can motivate decision makers to reduce the price bid (Feng et al. 2015, Rapaccini 2015) leading to an under-pricing of the PSS offering. In addition, services are heterogeneous which means different providers offer different quality levels (Fisk et al. 1993) and makes offers 
between competitors less comparable. Furthermore, PSS are typically long-term arrangements in comparison to product sales. PSS can span, for example, five years or longer (Kreye et al. 2015) which reduces the ability to accurately forecast the cost because of increasing uncertainty of longer time horizons (Goodwin and Wright 1993). Thus, PSS providers face high levels of uncertainty in their pricing decisions (Ottesen and Grønhaug 2002, Selviaridis and Spring 2010).

In current practice, pricing decisions rely on the decision makers' judgment of the available information based on their intuition and experience to identify a suitable bid (Pemer et al. 2014). High levels of uncertainty negatively impact the ability of decision makers to rely on their judgment as highlighted by psychology research (Tversky and Kahneman 1974, Ottesen and Grønhaug 2002). Many studies describe that decision makers ignore or underestimate uncertainty which means they are overconfident in their decisions (Tversky and Kahneman 1974, Zotteri and Kalchschmidt 2007). For example Langer \& Roth (1975) found that decision makers can feel more confident in predicting the future outcome of a throw of coins when past predictions have been correct. In other situations, uncertainty can be overestimated (Harvey 2001). Thus, it is the decision maker's perception of uncertainty that determines pricing decisions; however, the current servitization literature offers limited insights regarding this issue.

To address this challenge, this paper aims to investigate the following research question (RQ): What impact does the existence of competition have on the providers' pricing decision for PSS under uncertainty? To answer this RQ, an empirical study is introduced to investigate the decision maker's reaction to a bidding scenario with and without the existence of competition. This empirical study followed an experimental design and was undertaken with industrial costing and bidding experts, mainly from the 
defence and aerospace industry. Our research contributes to the servitization and PSS literature in two ways. First, our findings investigate decision-making at the competitive bidding stage for PSS provision and show that predictions from current theory are not confirmed within the context of PSS. Second, we show relevant uncertainty sources that influence the decision making and identify two sources that have thus far received limited attention: namely the internal processes of the PSS provider and customer related uncertainty.

\section{Background}

This section reviews the literature on PSS, pricing strategies for PSS and uncertainty in competitive bidding for PSS.

\subsection{Product-Service Systems}

Product-Service Systems integrate elements of product and service offerings so that the individual product or service part of the system cannot be distinguished anymore (Tukker 2004, Kreye 2016). For example, for the delivery of an output-focused PSS for a fleet of aircraft, the provider may exchange the physical aircraft (or parts of it) to guarantee availability and undertake necessary, maintenance activities away from the customer site. The aircraft becomes part of the service bundle which creates an integrated offering to deliver customer value (Wise and Baumgartner 1999). Thus, PSS have specific characteristics that distinguish them from individual product and service offerings. Specifically, the following three characteristics are important for the focus of this research.

First, PSS are not homogeneous, similar to many services. This means that offerings differ depending on the provider and customer involved in the arrangement (Fisk et al. 1993, Lacoste and Johnsen 2015, Kreye 2017). The specific PSS offering 
depends on the provider's capabilities including the technology and knowledge they have available (Oliva and Kallenberg 2003) and on the customer capability including their capability to provide the relevant information and access (Hawkins et al. 2015). Second, PSS offerings have typically high operational complexity which differs between specific offerings (Kreye et al. 2015). In this context, complexity can be defined as the number of independent tasks necessary to deliver the service (Shostack 1987, Skaggs and Youndt 2004). For example, the maintenance of a product or similar after-sales services require less complexity than performance-based services. Thus, PSS offerings require more developed and mature operational processes and delivery systems. Third, PSS are long-lived because many of the supported pieces of equipment have long life expectancies - often spanning multiple decades. Similarly, the PSS arrangements for these pieces of equipment are also long-term in nature. Typical contract lengths in the defence and aerospace industry are five-year contracts (Kreye et al. 2012). This creates difficulties with regard to forecasting as future costs (Settanni et al. 2014) may depend on future market developments, customer's future needs and use rates as well as the provider's future capabilities (Goh et al. 2010).

These characteristics create specific challenges for the pricing of PSS, specifically in competitive-bidding settings. PSS offerings are difficult to compare between different providers due to their non-homogeneous nature. Further, customers and providers may find it difficult to realistically evaluate the PSS offerings on the market because of the highly-complex nature of the involved operations. Finally, providers face high levels of uncertainty connected to forecasting the cost and operational need of providing a PSS, which has impact on their decision making. Thus, developing a suitable pricing strategy is a core challenge of PSS providers. 


\subsection{Pricing of PSS in competitive bidding}

Much of the literature on competitive bidding focuses on non-integrated product or service offerings and aims typically at determining optimal bidding strategies (Puro et al. 2011, Cai et al. 2012). As described above, PSS differ from products with regard to heterogeneity of offerings between competitors, operational complexity and the long contract durations which has important implications for the pricing of these offerings. PSS prices should be determined based on the value they deliver to the customer (Oliva and Kallenberg 2003). However, this value is difficult for the provider to determine and quantify. They create the challenge of comparison between different providers where multiple attributes apart from service price need to be considered (Ellram and Tate 2015, Hawkins et al. 2015). These attributes depend on the specific context and can include physical facilities (Ballesteros-Pérez et al. 2016), staff skills and empathy (Parasuraman et al. 1988) and other providers' capabilities. As a result, much of the literature in competitive bidding has focused on service of low complexity which can be compared between providers. Examples here are transport services (Berling and EngLarsson 2016), hotel services (Ballesteros-Pérez et al. 2016) and restaurants (Arenoe et al. 2015). Thus, existing approaches have limited applicability for PSS which are highly complex and long-lived.

\subsection{Uncertainty in pricing PSS}

High levels of uncertainty can influence the pricing of PSS. This uncertainty can arise from various sources and thus impact the decision-making process (Kreye et al. 2014). These sources include the bidding context, internal processes and customer relationship. Table 1 summarises these different uncertainty sources and explains their relevance for the research presented in this paper. The literature has paid much effort on researching 
the impact of the bidding context (Schoenherr and Mabert 2008, Cai et al. 2009, Li and Graves 2012), the organizational processes for providing the PSS (Baines and Lightfoot 2014, Kreye et al. 2015) and the impact of customer relations on the bidding process (Guo et al. 2009, Chaneton and Vulcano 2011, Sošić 2011). In contrast, the impact of the existence of competition when bidding for PSS has been under-researched in the literature. This is therefore the focus of our research.

\section{<Please include Table 1 about here $>$}

\section{Expectations and hypothesis development}

This section will outline the expectations of our empirical observations regarding the impact of competition on pricing decision making. Rapaccini (2015) found that in practice many servitized manufacturers use a cost-based approach for pricing their PSS offerings. The reason for their observation may be found in the product-focused tradition of their businesses. We will thus focus our investigations on cost-based pricing due to the frequent use in practice. As such, our investigations will focus on four main elements: the cost estimate for fulfilling the PSS requirement, the desired profit margin, the first price bid (from which negotiations with the customer could start) and the minimum price bid (below which the provider will not accept the contract). The investigated independent variable is the existence of competition. Figure 1 depicts the research design.

\section{<Please include Figure 1 about here $>$}

As described above, the introduction of competition to a bidding scenario adds further uncertainty. Yet, a cost estimate is typically based on operational considerations for fulfilling the PSS requirements (Goh et al. 2010). It thus includes a level of uncertainty relevant for the cost estimate such as cost of spare parts, assumptions about staff times 
and equipment wear out (Kreye et al. 2012). We therefore do not expect to see a difference in the decision maker's choice of cost estimate based on the introduction of competition to a bidding scenario. We state the following hypothesis:

H1: The chosen cost estimate is not influenced by the existence of competition when bidding for the provision of PSS.

The additional uncertainty introduced through competition may influence the decision maker's consideration regarding the desired profit margin and the price bids. The introduction of competition may cause the decision maker to evaluate the likely price bids of competitors (Ballesteros-Pérez et al. 2016) and hence adjust their own expectations of achievable profit margins. Specifically we would expect increased pressures for providers who in turn reduce their profit margins and reduced first price bid (Stark and Rothkopf 1979). We thus state the following hypotheses:

H2: Decision makers reduce their stated profit margins when competition is introduced to a bidding scenario for PSS provision.

H3: Decision makers reduce their initial price bids when competition is introduced to a bidding scenario for PSS provision.

Finally, we expect that the minimum price bid remains unchanged due to the introduction of competition. The reason for this expectation is that a minimum price bid is often based on the lowest acceptable profit (Kreye et al. 2012). The decision maker will orient themselves on the cost estimate (i.e. hypothesis 1). We can thus formulate the following hypothesis.

H4: Decision makers do not reduce the minimum price bid they find acceptable for providing PSS when competition is introduced to a bidding scenario for PSS provision. 


\section{Method}

To answer our RQ, an empirical study was designed following an experimental set-up using questionnaires. This was deemed suitable for this research due to two reasons. First, for the purpose of this research we needed a data collection method that required a minimal level of interaction between the researcher and the participants. This minimised the influence of bias and preconception, offered the ability to determine the participants' attitudes and beliefs (Teddlie and Tashakkori 2009). Second, we needed to address a larger set of participants to enable comparison between the different attitudes and responses of decision makers. This supported generalizability of the findings across organisations and industrial sectors.

\subsection{Research design}

The unit of analysis for this research is the individual decision maker. To enable a comparison between different bidding scenarios, a two-step research design was used. As such, the study consisted of two individual questionnaires which were administered on paper. Both questionnaires contained a PSS bidding scenario and included a qualitative description of the decision problem and a graphical display of the cost forecast as shown in Figure 2. The general bidding scenario was the same in both questionnaires: the participants were in the situation of bidding for a 5-year service contract for one of the company's lathes. This general bidding scenario was chosen for the following reasons. The characteristics of a lathe could be expected to be known to the participants in enough detail due to their engineering background. Further, the study participants did not operate in the lathe industry which meant that none of the participants had specific in-depth knowledge about the business conditions and technical details. Thus, we can assume a similar level of background knowledge which 
reduces the influence of bias and makes the responses comparable between participants. The graphical display of the cost forecast was chosen as a fan diagram as this was described in the literature to be easily understandable and support decision makers' interpretation of the data as well as make them aware of the influence of uncertainty on their decision (Kreye et al. 2012). To support this understanding a description of the general meaning of the graph was given with the scenario to explain the labelling and graph meaning. The text of the further description is included in the Appendix A.

\section{<Please include Figure 2 about here>}

\subsection{Questionnaire design}

In both questionnaires, the general bidding scenario focused on an open tender similar to industrial standards familiar to the study participants. The two questionnaires differed as follows. The first questionnaire (Scenario "no explicit competition") utilized terms such as "negotiate" and "tender" in order not to bias the participants. The existence of competition was neither mentioned in nor excluded from the scenario. The reason for this methodological choice was to not bias the participants towards competition-based pricing (Rapaccini 2015). If the existence of competition is known in a bidding scenario, pricing decisions are often simplified because decision makers may orient themselves on the expectations of competitor bids (Ballesteros-Pérez et al. 2016). Thus, the mentioning of competition - also in a statement highlighting the lack of competition - can bias decision making and thus limit the insights with regard to our research question. Thus, the term competition was not utilised in the first questionnaire to limit the influence of bias on the decision outcomes. This assumption was left to the participant to make. Other assumptions the participants had to make were about the bidding strategy of the customer, their budget limits, preferences or beliefs. 
The second questionnaire (Scenario "explicit competition”) explicitly mentioned the existence of competition. It was assumed that the competitors had access to the same cost information as the participant and had sufficient knowledge about the processes of maintaining the lathes. Uncertainties influencing the decision were exemplified as the bidding strategy of the opponents, the price bids of the competitors and their overall service budget. Questionnaire 2 also contained an additional scenario where the customer requested a further reduction of the price bid. The participants were asked to respond to this request and give their reasoning for their response. This additional scenario was exploratory in nature to study the possibility of changing the bidding strategy of the decision maker when facing a more specified negotiation with the customer.

The two questionnaires were handed out with a time difference. This allowed studying the effect of the changed scenario and limiting the influence of memory from answering the "no explicit competition" scenario. A further advantage was that it kept the participants in the same decision context reducing the influence of other factors such as a change of emotions (Schwarz 2000), stress levels (Cannon-Bowers 1998) or the decision context (Adair 1984, Robson 2011). The empirical study was undertaken at a one-day industrial conference on cost forecasting. The "no explicit competition" questionnaire was handed out and collected early in the morning and the "competition" one in the afternoon. In between the questionnaires the participants were engaged in intellectual activities including presentations on costing practices in industry and informal discussions on current issues in the field. The time difference was chosen to be a long enough for the participants to forget the details such as wording of their previous answers (Cooke et al. 2002) and short enough to not change the overall decision situation. 
The questions focused on the cost-based pricing approach as a suitable method for PSS (Rapaccini 2015) and investigated the cost estimate, the profit margin, the first and the minimum price bid. In addition to these evaluations, the participants were asked to give reasons for their choices and verbal evaluations of the bidding scenario. These were phrased as open questions to encourage unbiased verbal answers. This approach enabled the researchers to gather quantitative information to test the research hypotheses while also enabling to capture the participants' qualitative reasoning and thought processes. Finally, the participants were asked to list the risks or uncertainties that they found important for their decision making. Both terms were used interchangeably here to account for the close link in industrial understanding (Kreye et al. 2013).

\subsection{Participants}

The study was carried out at a conference of the Society for Cost Analysis and Forecasting (SCAF) and a conference of the Association of Cost Engineers (ACostE), both situated in the UK (ACostE 2012, SCAF 2012). The all-day conferences were attended by costing and bidding experts from the defence and aerospace sector and were thus acquainted with the concept of PSS and competitive bidding. The participants were predominantly male and were decision makers with more than five years of experience in the field and in costing and pricing. Furthermore, most participants were employees of large and international organisations. We applied the self-selection volunteer sampling as suitable approach where each individual participant could choose individually if they wanted to participate in this study (Saunders et al. 2012). This approach was deemed suitable for the purpose of our study for the following reasons. It allowed the participants to evaluate their desire to respond to the questionnaires (Saunders et al. 2012). They were thus not put under stress or pressure which could 
have biased the responses. We ensured high response rates by handing physical copies of the questionnaires out at the conferences that were attended by persons with relevant background knowledge in costing and pricing. The total number of returned questionnaires was 39 for the "no explicit competition" scenario and 32 for the "competition" scenario out of which 28 were traceable, i.e. the results of both scenarios could be compared.

When answering the questionnaires, the participants worked separately without communicating with each other, which was ensured through supervision by the researchers and the conference organisers. The participants were asked about their experience with a fan diagram as a graph to display uncertain forecasting information. The responses indicated that $54 \%$ had seen a diagram like the one presented before, $43 \%$ had not and 3\% did not give an answer. Further, the participants were asked to state the interpretation of a fan diagram in their own words. This ensured that they understood the diagram as a basis for decision making. The responses suggest that most respondents $(82.1 \%)$ related it to the concept of uncertainty as defined in this research. The remaining participants did either give no response or indicated a different interpretation. The answers suggest that the study participants understood the purpose of the fan diagram, could interpret and describe it in their own words. The fan diagram was thus deemed a suitable approach to displaying information for the purpose of this study.

\subsection{Data analysis}

The responses were analysed using a mixed-method approach. The comparison of the decision outcome with regard to cost estimate, profit margin and price bids were analysed quantitatively via statistical analysis using a t-test. The t-test has been highlighted as being suitable for sample sizes smaller than 30 (Lapin 1987, p. 365) and is thus suitable for the number of responses of this study. The t-test was used to 
compare the mean values of the two samples (i.e. comparing responses to

Questionnaires 1 and 2). Furthermore, we applied qualitative data analysis to the open questions such as the influencing factors for setting the minimum price and risks/uncertainties influencing the participants' responses. These were initially coded based on the researchers' understanding and interpretation of the data and subsequently combined to identify emerging themes through systematic combining (Dubois and Gadde 2002).

\section{Findings}

This section presents the findings with regard to the chosen cost estimates, profit margins, pricing decisions, uncertainty factors and additional reduction of the price bid. Table 1 outlines the basic statistics of the main responses with regard to the cost estimate, profit margin and the first and minimum price bids.

\section{<Please insert Table 2 about here $>$}

\subsection{Cost estimates}

Most respondents gave their cost estimate in the form of a percentage line within the given fan diagram; only five respondents gave absolute cost values. The findings showed that the chosen cost estimates moved closer to the medium value of the forecast range (i.e. the $50 \%$ mark) with the introduction of competition. Eleven participants (39.3\%) reduced their cost estimate when competition was introduced to the scenario. This is an unexpected outcome as the costs are usually not lower due to competitors offering the same service. On the other hand, 16 participants $(57.1 \%)$ did not change their cost estimate but chose the same (point) forecast. In general, the stated cost estimates with the introduction of competition were lower than the cost estimates without competition $(\mathrm{p}<0.05$, two-tailed t-test). We thus did not confirm hypothesis 1 of 
our research.

\subsection{Profit margins}

The stated profit margins were in a range between 5\% and 20\%. Most of the participants stated $10 \%$ as their ideal profit margin for the described contract. The second most common selection for both questionnaires was $15 \%$ margin. This is a nonsurprising finding for this set of participants as these are standard profit margins for the industrial sector. The results between the two questionnaires did not show a significant difference, which means that the stated profit margins were not changed due to the introduction of competition to the bidding scenario. Thus, we did not confirm hypothesis 2 of our research.

\subsection{Pricing decisions}

The study revealed interesting insights into the impact of competition on the first and minimum price bids. The first price bids were not significantly different between the two scenarios with the existence of competition. Only a weak statistically significant difference was found between the two scenarios $(\mathrm{p}<0.1$, one-tailed $\mathrm{t}$-test). This means that we did not confirm hypothesis 3 of our research. The minimum price bids showed no difference due to the introduction of competition. We did thus confirm hypothesis 4 of our research. Comparing price bids to the cost estimates (Section 4.1), a difference can be noticed: 11 participants reduced their cost estimate; only six reduced their first price bid and five reduced their minimum price bid. On the other hand, only one participant raised their cost estimate, five participants raised their first price bid, and six raised their minimum price bid. This means that the participants pursued different strategies with the different scenarios. Table 3 depicts the reaction of the participants to the introduction of competition to the scenario. 


\section{<Please insert Table 3 about here>}

\subsection{Uncertainty at the contract bidding stage}

In general the uncertainty sources identified in our literature review were also mentioned by the study participants. The given responses can thus be categorised into environmental uncertainty, internal processes for providing the PSS, customer-related uncertainty and competition uncertainty as listed in Table 4. Column 3 "frequency stated" shows the percentage of the participants who mentioned these uncertainties in the presented empirical study. These do not add up to 28 participants or $100 \%$, as the question was phrased as an open question and each participant could name as many uncertainties as s/he deemed were important. The percentages in Table 4 mark the amount that each of the categories was named out of every uncertainty entry. We list two columns with frequency values. The first column of frequency values is based on the total number of responses for the study participants. The second column of frequency values represent the findings excluding the uncertainties listed in the questionnaires due to the potential biasing effect. The findings show that the uncertainties connected to the internal processes of providing the PSS were considered as important by most of the participants. The least important category of this empirical study was the uncertainty arising from competition.

\section{<Please insert Table 4 about here>}

Table 4 shows examples that were named in the scenario descriptions as well as independent examples identified by the participants. Each of the named uncertainty sources included examples that were independently identified by the participants. However, specifically the examples with regard to environmental uncertainty and customer-related uncertainty were identified independently by the participants. In other 
words, the responses mentioning these sources were not biased by the study set-up. We can thus summarise that these were very important uncertainty sources for the bidding decisions.

\subsection{Additional reduction of price bid}

The additional scenario was to further reduce the price bid (beneath the previously named minimum price) when asked by the customer. Most of the participants (71.4\%) refused a further price reduction in the described scenario. The stated reasons included the need to make profit, the too high risk of losses, the argumentation of the previous calculation being correct, and the inability to further reduce the uncertainty. The $28.6 \%$ of participants who stated they would accept a further reduction, argued that they could reduce the profit, remove further uncertainties, take the risk of making a loss, the need for the cash flow, and to adjust the costs (without an explanation how this could be achieved). Table 5 depicts the results of the additional scenario and shows the relative importance of these categories.

\section{$<$ Please insert Table 5 about here $>$}

\section{Discussion}

This section discusses the study findings with regard to the RQ.

\subsection{Pricing of PSS in competitive bidding}

The presented study did not confirm most of the expectations from the literature with regard to pricing of PSS in competitive bidding. In particular the findings for the cost estimate (hypothesis 1) showed significant differences when competition was introduced to the bidding scenario. This contradicts expectations from the literature because the costs of fulfilling the PSS requirements do not change due to the existence 
of competition (Goh et al. 2010). There could be two possible explanations for this observation. First, the behavioural considerations are an important factor for decision making under uncertainty which change the decision maker's judgment and evaluations of the bidding situation. These behavioural impacts can lead to the observations of irrational decision making (Radner 2000, Huang et al. 2013) such as the reductions of the cost estimate when competition is introduced to the bidding scenario. The reason for such behaviour can be found in the decision maker's inability to assess the uncertainty accurately and consider it in their decision making (Kreye et al. 2012). Second, the decision maker may expect that their company needs to reduce the cost of providing the PSS over the contract duration through, for example, developing relevant capabilities (Reinartz and Ulaga 2008). Thus, the decision maker may expect that the assumptions of the cost estimate will not hold over the full duration of the PSS contract and savings can be achieved. This suggests that the existence of competition increases pressures on providers to reduce their costs which the decision maker includes in their evaluations of the pricing decision. Our study findings thus call for behavioural investigations into decision making in competitive bidding for PSS including the cognitive processes of the decision maker.

The presented study also did not support hypotheses 2 and 3 . This contradicts current descriptions of the motivation of competition in bidding as a general reduction of the prices (Stark and Rothkopf 1979). The findings may be due to the industrial context of the participants. The UK aerospace and defence industry is focused around servicing a specific customer which is a government-funded organisation. Thus, the customer has relatively high bargaining and negotiation power. The findings suggest that the impact of the customer is more important than the existence of competition. This would explain the lack of observing any significant difference between the price 
bids in the bidding scenarios without and with competition. However, a further reduction of the price bid was refused by the majority of the study participants. Thus, other considerations were also important for the decision makers in our empirical study which requires further investigations to identify reasons and causes.

The findings did confirm hypothesis 4 of our research. Despite the reduction of cost estimates, the participants did not reduce the minimum price bid they would accept for the PSS. These observations may be due to the nature of the aerospace and defence industry which can be described as an oligopoly where few competitors are able to bid for the provision of highly complex PSS (Kreye et al. 2013). However, it also links to the characteristics of PSS as outlined by the literature which are not homogeneous and are thus difficult to be compared between different providers. This observation thus suggests that providers retain competitive advantage through the nature of their specific PSS offering. This competitive advantage goes beyond the price bid and includes quality characteristics (Ellram and Tate 2015, Hawkins et al. 2015) connected to the PSS.

\subsection{Uncertainty in pricing PSS}

The findings suggested the role of different uncertainty sources and their importance in influencing the decision making of competitive bidding for PSS. Specifically internal processes for providing the PSS were the most frequently named source of uncertainty. This confirms suggestions from the literature such as Benedettini et al. (2015) and Kreye (2017) who describe that most PSS providers who fail in their attempt of becoming servitized and do so because of internal risks. Our findings extend the literature by linking the internal sources of uncertainty as a main influence to decision making in competitive bidding for PSS. This is an important finding because internal processes are under the provider's control (Schmidt and Wei 2006) and can thus be 
managed and resolved. However, further investigations need to identify how the uncertainty arising from different aspects of the internal processes in PSS providers can be resolved.

Specifically, the cost estimate was determined as a major cause of internal uncertainty. One of the reasons for this observation may be that the participants were cost estimators and bidding decision makers which highlighted their expertise in this area. Despite this, the findings also demonstrate the characteristic of PSS as being longterm commitments and highlights the difficulty of long-term forecasts and future uncertainty (Goh et al. 2010). This is a core difference between existing models of competitive bidding described in the literature which focus on products or short-term services. Thus, PSS form a specific context for competitive bidding.

Another important source of uncertainty named in the study arose from the customer and their utilisation rates of the machine and the uncertainty in future contracts and further orders. This observation may again be connected to the specific context of the UK aerospace and defence industry because of the high market power of the customer. However, this observation also highlights the long-term relationship between provider and customer (Dwyer et al. 1987, Kreye et al. 2015) - here considered in the form of future contracts and orders. This links to descriptions in the literature that describe PSS as requiring close and long-term collaboration between provider and customer. The input of the customer creates variability in the production process (Kreye 2017) and creates additional challenges at the competitive bidding stage. The competitive bidding decision can be viewed as one instance within a long-term relationship between provider and customer and is impacted by the previous experience in this existing relationship (Kreye et al. 2013). Reversely, the future of this relationship is also impacted by the decisions made in the competitive bidding process - both 
positively and negatively. Our research depicts the importance of this uncertainty source in comparison to other sources for the decision maker in competitive bidding.

\subsection{Limitations}

The research limitations are related to the nature of the presented empirical study. Our study was designed as a closed experiment to investigate the issue of a stand-alone decision problem (Saunders et al. 2012). This also includes that the participants were excluded from their usual original organisational and political environment and put into the laboratory environment of the bidding scenario. Thus, not all possible factors that may influence a bidding decision in practice could be studied (Goodwin and Wright 1993). For example, factors such as the long-term relationship with the customer (Kreye 2017), the overall political situation in the country or the organisation's internal politics could potentially influence the decision maker's behaviour. We addressed these limitations by including the study within the professional environment of a workshop connected with the focus of our research. The participants were experts on the topic of cost forecasting and the interpretation of cost forecasts for making pricing decisions belonged to their professional work.

\section{Conclusions}

This paper aimed to investigate the research question (RQ): What impact does the existence of competition have on the providers' pricing decision for PSS under uncertainty? Presenting insights from an empirical study using an experimental set-up, we showed how pricing decisions are impacted through the existence of competition in the bidding scenario and the role of uncertainty in this context. Our research offered four main insights. First, we found that the evaluation of the cost estimate changed with the introduction of competition which contradicts expectations from current theory. 
Second, we found that profit margins and first price bid do not change with the introduction of competition. This also contradicts expectations from theory. Third, the minimum stated price bids did not change with the introduction of competition which confirms our expectations. Finally, our findings indicate the different sources of uncertainty that impact the decision makers' evaluations and judgment when competitive bidding for the provision of PSS. Specifically, the participants named internal processes, environmental uncertainty, customer-related uncertainty and competition uncertainty as relevant influences on their decision making.

Our research contributes to the literature in the field in the following two ways. First, we present insights in the decision-making at the competitive bidding stage for PSS provision. Specifically we showed that predictions from current theory offered only limited support within the context of PSS. Reasons for this can be seen in the decision maker's evaluations and judgment under uncertainty which may differ from expectations of rationality in the extant literature. Second, we showed the relevant uncertainty sources influencing the decision making in competitive bidding. Specifically, we identified uncertainty sources that have yet received limited attention within the PSS literature. As such, both internal processes of the PSS provider and customer-related uncertainty were named as a relevant and important uncertainty sources.

This research offers important managerial implications. First, judgment and subjective evaluations were shown to be important in competitive bidding. Thus, the decision maker needs to be able to evaluate the high levels of uncertainty they are exposed to at this stage in order to identify a suitable price bid and avoid under-pricing their offerings. This suggests that relevant decision support tools are needed to identify the influencing factors and guide the decision making process. Second, personal 
characteristics of the bidding decision maker may determine their interpretation of uncertainty and hence the chosen price bid. Specifically the ability to judge and evaluate available data can impact the decision and ultimately the bidding outcome. Thus careful considerations need to be given to the choice of decision maker to avoid systematic bias and ensure the success of the service business.

Our research points towards important areas that need further investigations. First, our study pointed towards the importance of internal sources of uncertainty connected to the processes for providing the PSS. Examples are the uncertainty connected to the cost estimate and the performance of the supported product. Further work is needed in investigating these internal sources of uncertainty and developing relevant support for PSS providers in responding to them. Second, the pricing decisions were found to be influenced by high levels of judgment and subjective evaluations. Thus, further work needs to investigate the cognitive processes behind these evaluations to identify what factors determine the finding of a suitable price bid. Third, our research highlighted the long-term relationship to the customer as an important source of uncertainty for PSS providers. This uncertainty source has thus far received limited attention in the literature and needs thus further investigation. Specifically the impact of the relationship on decision making in pricing and PSS operations is an important area for further work.

\section{References}

ACostE, 2012. ACostE Conference [online]. Available from: http://www.acoste.org.uk/template_content_F.php?page_id=481\&track=Conferenc e.

Adair, J. G., 1984. The Hawthorne Effect: A Reconsideration of the Methodological Artifact. Journal of Applied Psychology, 69 (2), 334-345. 
Arenoe, B., van der Rest, J.-P. I., and Kattuman, P., 2015. Game theoretic pricing models in hotel revenue management: An equilibrium choice-based conjoint analysis approach. Tourism Management, 51, 96-102.

Babcock, 2012. Australian Anzac Support Contract Win [online]. Available from: http://www.babcock.co.uk/media-centre/babcock-australian-anzac-supportcontract/.

Baines, T. and Lightfoot, H. W., 2014. Servitization of the manufacturing firm: Exploring the operations practices and technologies that deliver advanced services. International Journal of Operations \& Production Management, 34 (1), 2-35.

Ballesteros-Pérez, P., Skitmore, M., Pellicer, E., and Gutiérrez-Bahamondes, J. H., 2016. Improving the estimation of probability of bidder participation in procurement auctions. International Journal of Project Management, 34 (2), 158172.

Baveja, S., Singh, J. G., and Ledingham, D., 2004. From Products to Services: Why It's Not So Simple. Harvard Management Update, 9 (4), 3-5.

Beckman, C. M., Haunschild, P. R., and Phillips, D. J., 2004. Friends or Strangers? Firm-Specific Uncertainty, Market Uncertainty, and Network Partner Selection. Organization Science, 15 (3), 259-275.

Benedettini, O., Neely, A., and Swink, M., 2015. Why do servitized firms fail? A riskbased explanation. International Journal of Operations \& Production Management, 35 (6), 946-979.

Berling, P. and Eng-Larsson, F., 2016. Pricing and timing of consolidated deliveries in the presence of an express alternative: Financial and environmental analysis. European Journal of Operational Research, 250 (2), 590-601.

Cai, G., Chao, X., and Li, J., 2009. Optimal reserve prices in name-your-own-price 
auctions with bidding and channel options. Production and Operations Management, 18 (6), 653-671.

Cai, G., Chen, Y.-J., and Gong, X., 2012. Design of online auctions: Proxy versus nonproxy settings. Decision Support Systems, 52 (2), 384-394.

Cannon-Bowers, J. A., 1998. Making Decisions under Stress: Implications for Individual and Team Training. Washington, DC, USA: American Psychological Association.

Chaneton, J. M. and Vulcano, G., 2011. Computing bid prices for revenue management under customer choice behavior. Manufacturing and Service Operations Management, 13 (4), 452-470.

Cooke, A., Zurif, E. B., DeVita, C., Alsop, D., Koenig, P., Detre, J., Gee, J., Pinãngo, M., Balogh, J., and Grossman, M., 2002. Neural basis for sentence comprehension: Grammatical and short-term memory components. Human Brain Mapping, 15 (2), $80-94$.

Defense Industry Daily, U. K., 2011. UK's Eurofighters Fly To Availability-Based Contracting [online]. Available from: http://www.defenseindustrydaily.com/ukseurofighters-fly-to-availability-based-contracting-04337/.

Dubois, A. and Gadde, L. E., 2002. Systematic combining: An abductive approach to case research. Journal of Business Research, 55 (7), 553-560.

Dwyer, F. R., Schurr, P. H., and Oh, S., 1987. Developing Buyer-Seller Relationships. Journal of Marketing, 51 (2), 11-27.

Ellram, L. and Tate, W. L., 2015. Redefining supply management's contribution in services sourcing. Journal of Purchasing and Supply Management, 21 (1), 64-78.

Feng, C., Fay, S., and Sivakumar, K., 2015. Overbidding in electronic auctions: factors influencing the propensity to overbid and the magnitude of overbidding. Journal of 
the Academy of Marketing Science, 1-20.

Fisk, R. P., Brown, S. W., and Bitner, M. J., 1993. Tracking the Evolution of the Services Marketing Literature. Journal of Retailing, 69 (1), 61-103.

Goel, R., 2007. Research spending under regulatory uncertainty. The Journal of Technology Transfer, 32 (6), 593-604.

Goh, Y. M., Newnes, L. B., Mileham, A. R., McMahon, C. A., and Saravi, M. E., 2010. Uncertainty in Through-Life Costing - Review and Perspectives. IEEE Transactions on Engineering Management, 57 (4), 689-701.

Goodwin, P. and Wright, G., 1993. Improving Judgmental Time Series Forecasting: A Review of the Guidance Provided by Research. International Journal of Forecasting, 9 (1993), 147-161.

Grönroos, C., 2011. A service perspective on business relationships: The value creation, interaction and marketing interface. Industrial Marketing Management, 40 (2), $240-247$.

Guo, P., Liu, J. J., and Wang, Y., 2009. Intertemporal service pricing with strategic customers. Operations Research Letters, 37 (6), 420-424.

Harvey, N., 2001. Improving Judgement in Forecasting. In: Armstrong, J. S., ed. Principles of forecasting: A handbook for researchers and practitioners. New York, NY, USA: Springer Science \& Business Media, 59-80.

Hawkins, T. G., Gravier, M. J., Berkowitz, D., and Muir, W. A., 2015. Improving services supply management in the defense sector: How the procurement process affects B2B service quality. Journal of Purchasing and Supply Management, 21 (2), 81-94.

Huang, T., Allon, G., and Bassamboo, A., 2013. Bounded Rationality in Service Systems. Manufacturing \& Service Operations Management, 15 (2), 263-279. 
Kleemann, F. C. and Essig, M., 2013. A providers' perspective on supplier relationships in performance-based contracting. Journal of Purchasing and Supply Management, $19(3), 185-198$.

Kreye, M. E., 2016. Employee motivation in Product-Service-System providers. Production Planning \& Control, accepted (September), 1-11.

Kreye, M. E., 2017. Relational uncertainty in service dyads. International Journal of Operations \& Production Management, in print.

Kreye, M. E., Goh, Y. M., Newnes, L. B., and Goodwin, P., 2012. Approaches of Displaying Information to Assist Decisions under Uncertainty. Omega International Journal of Management Science, 40 (6), 682-692.

Kreye, M. E., Newnes, L. B., and Goh, Y. M., 2013. Information availability at the competitive bidding stage for service. Journal of Manufacturing Technology Management, 24 (7), 976-997.

Kreye, M. E., Newnes, L. B., and Goh, Y. M., 2014. Uncertainty in competitive bidding - a framework for product - service systems. Production Planning \& Control, 25 (6), 462-477.

Kreye, M. E., Roehrich, J. K., and Lewis, M. A., 2015. Servitising manufacturers: the impact of service complexity and contractual and relational capabilities. Production Planning \& Control, 26 (14), 1233-1246.

Lacoste, S. and Johnsen, R. E., 2015. Supplier-customer relationships: A case study of power dynamics. Journal of Purchasing and Supply Management, 1-12.

Langer, E. J. and Roth, J., 1975. Heads I Win, Tails is Chance: The Illusion of Control is a Function of the Sequence of Outcomes in a Purely Chance Task. Journal of Personality and Social Psychology, 32 (1975), 951-955.

Lapin, L. L., 1987. Statistics for Modern Business Decisions. 4th ed. San Diego, CA, 
USA: Harcourt Brace Jovanovich Publishers.

Li, H. and Graves, S. C., 2012. Pricing decisions during inter-generational product transition. Production and Operations Management, 21 (1), 14-28.

Oliva, R. and Kallenberg, R., 2003. Managing the transition from products to services. International Journal of Service Industry Management, 14 (2), 160-172.

Oosterhuis, M., van der Vaart, T., and Molleman, E., 2011. Perceptions of technology uncertainty and the consequences for performance in buyer-supplier relationships. International Journal of Production Research, 49 (20), 6155-6173.

Ottesen, G. G. and Grønhaug, K., 2002. Market orientation and uncertain supply in upstream markets: An exploratory study. European Journal of Purchasing and Supply Management, 8, 209-219.

Parasuraman, A., Zeithaml, V. A., and Berry, L., 1988. SERVQUAL: A Multiple Item Scale for Measuring Consumer Perceptions of Service Quality. Journal of Retailing, 64 (1), 12-40.

Pemer, F., Sieweke, J., Werr, A., Birkner, S., and Mohe, M., 2014. The cultural embeddedness of professional service purchasing-A comparative study of German and Swedish companies. Journal of Purchasing and Supply Management, $20(4), 273-285$.

Puro, L., Teich, J. E., Wallenius, H., and Wallenius, J., 2011. Bidding strategies for real-life small loan auctions. Decision Support Systems, 51 (1), 31-41.

Radner, R., 2000. Costly and Bounded Rationality in Individual and Team Decisionmaking. Industrial and Corporate Change, 9 (4), 623-658.

Rapaccini, M., 2015. Pricing strategies of service offerings in manufacturing companies: a literature review and empirical investigation. Production Planning \& Control, 26 (14-15), 1247-1263. 
Reinartz, W. and Ulaga, W., 2008. How to Sell Services MORE Profitably. Harvard Business Review, 86 (5), 90-96.

Robson, C., 2011. Real World Research - A Resource for Users of Social Research Methods in Applied Settings. 3rd ed. Chichesteer, UK: John Wiley \& Sons Ltd.

Saunders, M. N. K., Lewis, P., and Thornhill, A., 2012. Research Methods for Business Students. 6th ed. Harlow, UK: Financial Times Prentice Hall.

SCAF, 2012. Society for Cost Analysis and Forecasting [online]. Available from: http://www.scaf.org.uk/.

Schmidt, M. R. and Wei, W., 2006. Loss of Agro-Biodiversity, Uncertainty, and Perceived Control: A Comparative Risk Perception Study in Austria and China. Risk Analysis: An International Journal, 26 (2), 455-470.

Schoenherr, T. and Mabert, V. A., 2008. The use of bundling in B2B online reverse auctions. Journal of Operations Management, 26 (1), 81-95.

Schwarz, N., 2000. Emotion, Cognition, and Decision Making. Cognition and Emotion, $14(1), 433-440$.

Selviaridis, K. and Spring, M., 2010. The dynamics of business service exchanges: Insights from logistics outsourcing. Journal of Purchasing and Supply Management, 16 (3), 171-184.

Settanni, E., Newnes, L. B., Thenent, N. E., Parry, G., and Goh, Y. M., 2014. A through-life costing methodology for use in product-service-systems. International Journal of Production Economics, 153, 161-177.

Shostack, G. L., 1987. Service Positioning Through Structural Change. Journal of Marketing, 51 (1), 34-43.

Skaggs, B. C. and Youndt, M., 2004. Strategic Positioning, Human Capital, and Performance in Service Organizations: A Customer Interaction Approach. 
Strategic Management Journal, 25 (1), 85-99.

Sošić, G., 2011. Impact of demand uncertainty on stability of supplier alliances in assembly models. Production and Operations Management, 20 (6), 905-920.

Stark, R. M. and Rothkopf, M. H., 1979. Competitive Bidding: A Comprehensive Bibliography. Operations Research, 27 (2), 364.

Teddlie, C. and Tashakkori, A., 2009. Foundations of Mixed Methods Research. Thoudand Oaks, CA, USA: Sage.

Tukker, A., 2004. Eight types of Product-Service System; eight ways to suistainability? Experiences from SUSPRONET. Business Strategy and the Environment, 13, 246260.

Tversky, A. and Kahneman, D., 1974. Judgment under Uncertainty : Heuristics and Biases. Science, 185 (4157), 1124-1131.

Vandermerwe, S. and Rada, J., 1988. Servitization of Business: Adding Value by Adding Services. European Management Journal, 6 (4), 314-324.

Wise, R. and Baumgartner, P., 1999. Go Downstream: The New Profit Imperative in Manufacturing. Harvard Business Review, 77 (5), 133-141.

Zotteri, G. and Kalchschmidt, M., 2007. Forecasting Practices: Empirical Evidence and a Framework for Research. International Journal of Production Economics, 108 (1-2), 84-99. 


\section{Appendix}

Scenario - no explicit competition (Questionnaire 1):

"You are the manager in a company producing $\mathrm{CNC}$ lathes working in the contract department. The company is about to negotiate a service contract with a customer for one of the company's lathes. The graph [Figure 1 in the manuscript] below shows the costs that might occur every year during the 5 year service period of Machine A.

Uncertainty arises for example from variability in labour rates, material prices, utilization of the machine and spares storage costs.

The lower graph labelled 5\% equals a 5\%-confidence limit that the future costs will be these or lower. The equivalent explanation can be given for 30\%, 50\%, $70 \%$ and $95 \%$ confidence limits. The graph labelled $50 \%$ is the baseline estimate derived from typical service histories for $\mathrm{CNC}$ lathes. The lower graph shows the minimum costs expected to occur if only preventive actions i.e. planned maintenance occurs. The upper graph is based on the assumption that more than anticipated repairs are encountered in service. You are asked to participate in the negotiation process with the customer for a service contract for Machine A. You are negotiating a yearly fee for the 5 year service contract. You do not have any information on the budget limits of the customer."

Addition for "competition" scenario (Questionnaire 2):

"The customer is in negotiation with other contractors for the same contract. It is assumed that the competitors have sufficient knowledge in maintaining Machine A without the need to contact your company. Your opponents have access to the same cost information as you.

Uncertainties connected to the opponents are:

- Their bidding strategy, 
- Their budget limits or price bids,

- Their overall service budget (including other contracts they have)."

Questions:

1) What cost estimate would you choose?

2) Why did you select this?

3) What profit margin would you add?

4) What would your first tender be?

5) What is the minimum price you would bid?

6) In your opinion, what are the influencing factors on setting this minimum price?

7) What risks/uncertainties have an influence on your decision? How did they impact your decision?

Additional question for "competition" scenario (Questionnaire 2):

"In the negotiation process you reached your bidding limit, i.e. the lowest you can go to maintain your expected profit margins. However, the customer comes back to you asking for a price reduction which could mean that at least one opponent has bid lower than you, or they have a lower budget. You have the choice of refusing that offer (and maybe affront the customer) or lower your bid (e.g. by reducing the profit margin or raising the risk to end up with a loss-generating contract)."

The questions asked about this scenario were:

1) Would you reduce your bid?

2) What would be the rationale/explanation for your reaction? 


\section{Tables and Figures}

Table 1: Uncertainty influencing the pricing strategy of PSS

\begin{tabular}{|c|c|c|}
\hline $\begin{array}{l}\text { Uncertainty } \\
\text { sources }\end{array}$ & Description & Challenge for PSS \\
\hline $\begin{array}{l}\text { Environmental } \\
\text { uncertainty }\end{array}$ & $\begin{array}{l}\text { Uncertainty arising from the external } \\
\text { environment. It includes factors such as } \\
\text { market developments (Beckman et al. } \\
\text { 2004), regulatory developments (Goel } \\
\text { 2007) and technology uncertainty } \\
\text { (Oosterhuis et al. 2011) }\end{array}$ & $\begin{array}{l}\text { Due to the long contract duration of } \\
\text { many PSS arrangements (Kreye et al. } \\
\text { 2014), external developments may } \\
\text { affect PSS providers by reducing the } \\
\text { operability and profitability. Thus, } \\
\text { unforeseen market developments can } \\
\text { challenge operations }\end{array}$ \\
\hline $\begin{array}{l}\text { Internal processes } \\
\text { for providing the } \\
\text { PSS }\end{array}$ & $\begin{array}{l}\text { Ability to meet the service requirements } \\
\text { of the tendered service. Ability to } \\
\text { accurately forecast the future cost of } \\
\text { providing the service and } \\
\text { develop/maintain the relevant } \\
\text { capabilities }\end{array}$ & $\begin{array}{l}\text { Includes the performance of the } \\
\text { product (breakdown rates and } \\
\text { functionality over the duration of the } \\
\text { agreement), ability to accurately } \\
\text { forecast the cost for providing the PSS } \\
\text { (Goh et al. 2010) }\end{array}$ \\
\hline $\begin{array}{l}\text { Customer } \\
\text { relationship }\end{array}$ & $\begin{array}{l}\text { Service operations dependent on both } \\
\text { customer and provider input (Kreye } \\
\text { 2017). Furthermore, the customer } \\
\text { relationship in B2B settings are impacted } \\
\text { by the long-term nature of the } \\
\text { relationships (Grönroos 2011) }\end{array}$ & $\begin{array}{l}\text { In PSS the nature of the customer } \\
\text { relationship is different than for } \\
\text { traditional manufacturing firms } \\
\text { because of the integrated nature of the } \\
\text { offering. Previous experience with the } \\
\text { customer may impact the pricing } \\
\text { decision (Kreye et al. 2013) }\end{array}$ \\
\hline Competition & $\begin{array}{l}\text { Existence of competition can create } \\
\text { uncertainty because they may underbid. } \\
\text { The uncertainty arises from a lack of } \\
\text { knowledge about the competitors' } \\
\text { capabilities including their cost } \\
\text { estimates, available technology and } \\
\text { knowledge and their experience on the } \\
\text { market (Kreye et al. 2014) }\end{array}$ & $\begin{array}{l}\text { Can impact the pricing of PSS when } \\
\text { knowing the identity of typical } \\
\text { competitors in the specific bid makes } \\
\text { pricing strategy easier to determine } \\
\text { (Ballesteros-Pérez et al. 2016). }\end{array}$ \\
\hline
\end{tabular}


Table 2: Descriptive statistics on quantitative responses

\begin{tabular}{|l|l|l|l|}
\hline Condition & Variable & Mean & $\begin{array}{l}\text { Standard } \\
\text { deviation }\end{array}$ \\
\hline No explicit & Cost estimate & $68 \%$ & $20.6 \%$ \\
competition & Profit margin & $11 \%$ & $3.4 \%$ \\
& First price bid (GBP) & 896 & 176.8 \\
& Minimum price bid (GBP) & 761 & 116.3 \\
\hline Competition & Cost estimate & $59.6 \%$ & $18.6 \%$ \\
(Questionnaire 2) & Profit margin & $10.9 \%$ & $3.5 \%$ \\
& First price bid (GBP) & 835.7 & 223.7 \\
& Minimum price bid (GBP) & 747.2 & 134.3 \\
\hline
\end{tabular}

Table 3: Comparison of the pricing strategy between "no explicit competition" and "competition" scenarios

\begin{tabular}{|c|c|c|c|c|c|}
\hline & Reduction & Raise & Level & \multicolumn{2}{|c|}{ Most stated values } \\
\hline \multirow[t]{2}{*}{$\begin{array}{l}\text { First } \\
\text { price bid }\end{array}$} & \multirow[t]{2}{*}{6} & \multirow[t]{2}{*}{5} & \multirow[t]{2}{*}{13} & \multicolumn{2}{|c|}{$\begin{array}{l}\text { No explicit competition } \\
\qquad \begin{array}{l}£ 1000(20.8 \%) \\
£ 1200(12.5 \%) \\
£ 900(12.5 \%) \\
£ 700(12.5 \%)\end{array}\end{array}$} \\
\hline & & & & Competition: & $\begin{array}{l}£ 800(20.8 \%) \\
£ 900(16.7 \%) \\
£ 1000(16.7 \%)\end{array}$ \\
\hline \multirow{2}{*}{$\begin{array}{l}\text { Minimum } \\
\text { price bid }\end{array}$} & \multirow[t]{2}{*}{5} & \multirow[t]{2}{*}{5} & \multirow[t]{2}{*}{14} & $\begin{array}{c}\text { No explicit co } \\
:\end{array}$ & $\begin{array}{l}\text { petition } \\
£ 800(16.7 \%) \\
£ 900(12.5 \%) \\
£ 700(12.5 \%)\end{array}$ \\
\hline & & & & Competition: & $\begin{array}{l}£ 800(25.0 \%) \\
£ 750(16.7 \%) \\
£ 700(12.5 \%)\end{array}$ \\
\hline
\end{tabular}


Table 4: Uncertainties in the contract bidding stage

\begin{tabular}{|c|c|c|c|}
\hline $\begin{array}{l}\text { Uncertainty } \\
\text { category }\end{array}$ & Examples & $\begin{array}{c}\text { Total } \\
\text { frequency }\end{array}$ & $\begin{array}{c}\text { Frequency } \\
\text { excluding } \\
\text { potentially } \\
\text { biasing } \\
\text { examples }\end{array}$ \\
\hline $\begin{array}{l}\text { Environmental } \\
\text { uncertainty }\end{array}$ & $\begin{array}{ll}\text { - } & \text { Inflation } \\
\text { - } & \text { Future trends, economic changes } \\
\text { - } & \text { Technology development }\end{array}$ & $34.2 \%$ & $34.2 \%$ \\
\hline $\begin{array}{l}\text { Internal processes for } \\
\text { providing the PSS }\end{array}$ & $\begin{array}{l}\text { - Inaccuracy of cost forecast and bounds in } \\
\text { the cost estimate* } \\
\text { - Uncertainty in cost factors such as labour } \\
\text { - } \text { rates and maintenance cost* } \\
\text { - } \quad \text { Rerformance of the machine, ageing* } \\
\text { - } \quad \text { Level of repairs needed }\end{array}$ & $55.2 \%$ & $36.8 \%$ \\
\hline $\begin{array}{l}\text { Customer related } \\
\text { uncertainty }\end{array}$ & $\begin{array}{l}\text { - Fluctuations in machine usage including } \\
\text { peak times and idle time } \\
\text { - Uncertainty in future contracts and further } \\
\text { orders }\end{array}$ & $31.6 \%$ & $31.6 \%$ \\
\hline $\begin{array}{l}\text { Competition } \\
\text { uncertainty }\end{array}$ & $\begin{array}{l}\text { - Uncertainty in competitor } \\
\text { - } \quad \text { Risk of loss of contract* } \\
\text { - } \quad \text { Competitors' experience with machine }\end{array}$ & $26.3 \%$ & $21.0 \%$ \\
\hline
\end{tabular}

* These examples were named in the questionnaire and may thus have biased the respondents to include them in their answers. 
Table 5: Results of an additional reduction of the price bid

\begin{tabular}{|c|c|c|c|}
\hline & \multirow[b]{2}{*}{ Frequency } & \multicolumn{2}{|l|}{ Justification } \\
\hline & & Categories & $\begin{array}{l}\text { Percentage } \\
\text { of } \\
\text { frequency }\end{array}$ \\
\hline Refusal & $71.4 \%$ & $\begin{array}{l}\text { - "Make profit": The own company needed to make profit } \\
\text { at reasonable risk with this contract. Further reductions } \\
\text { would lower the profit and thus make the business less } \\
\text { affordable. } \\
\text { - "Risk of losses": Further price reductions would enhance } \\
\text { the risk of making losses. } \\
\text { - "Correct calculation": Some participants argued that } \\
\text { their previously named minimum price bid was a result of } \\
\text { correct calculation and thus already includes the possible } \\
\text { risks that the company could take. Further reductions } \\
\text { would not be possible. } \\
\text { - "Uncertainty": The uncertainty included in the forecast } \\
\text { and their previous decisions cannot be reduced any } \\
\text { further. Therefore, the previously stated minimum price } \\
\text { already includes the minimum compensation for } \\
\text { uncertainty which cannot be reduced either. } \\
\text { - Other: Other reasons included the rejection of the price } \\
\text { reduction was based on the negotiation style. }\end{array}$ & $\begin{array}{l}25.0 \% \\
20.0 \%\end{array}$ \\
\hline Acceptance & $28.6 \%$ & $\begin{array}{l}\text { - "Reduce profit": further price reductions can be made } \\
\text { affordable if the profit margin is reduced, e.g. by } 25 \% \text {. } \\
\text { - "Remove uncertainty": reduction of uncertainty involved } \\
\text { in the scenario. Unfortunately, no examples or methods } \\
\text { were given. } \\
\text { - "Take risk": take higher risk of making losses (without } \\
\text { monetary compensation). } \\
\text { - "Cash flow": the importance of short term cash flows for } \\
\text { a company. } \\
\text { - "Adjust costs": adjust the cost estimate to justify the } \\
\text { further price reduction. }\end{array}$ & $\begin{array}{l}12.5 \% \\
25.0 \% \\
37.5 \%\end{array}$ \\
\hline
\end{tabular}




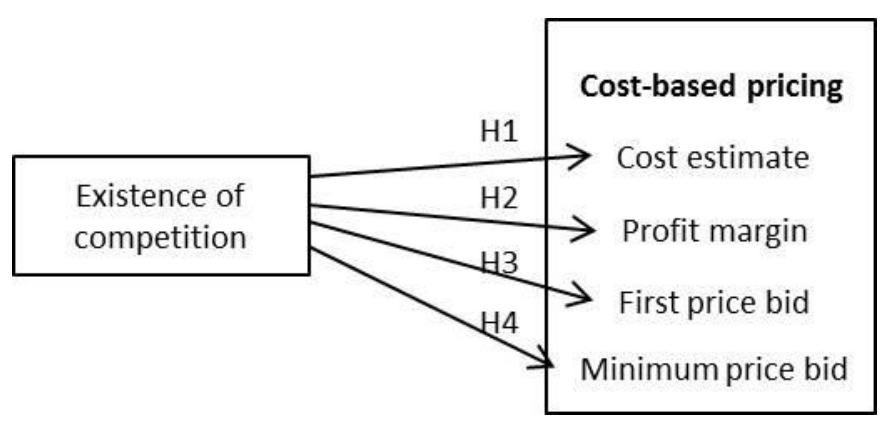

Figure 1: Theoretical design and hypotheses

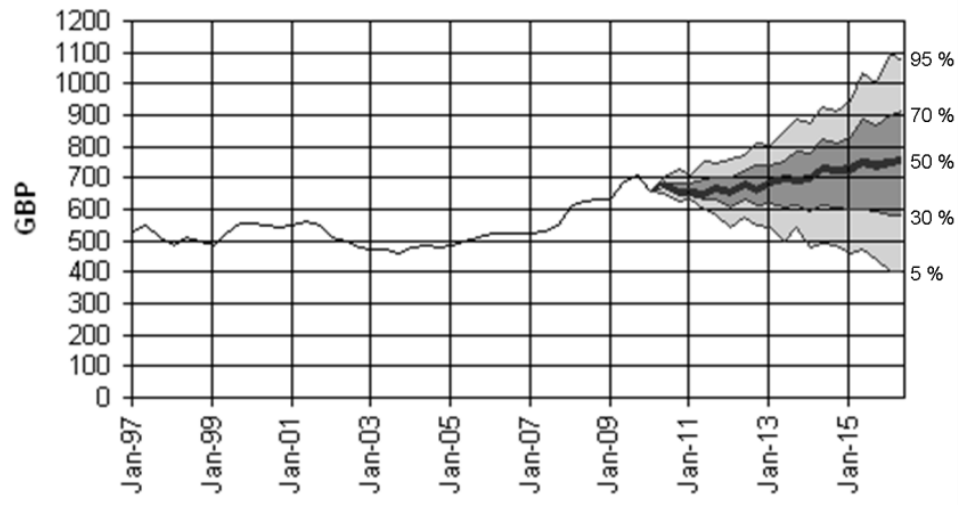

Figure 2: Graphical display of cost forecast in the questionnaires 


\section{Cost-based pricing}

Existence of competition

Cost estimate

Profit margin

First price bid

Minimum price bid

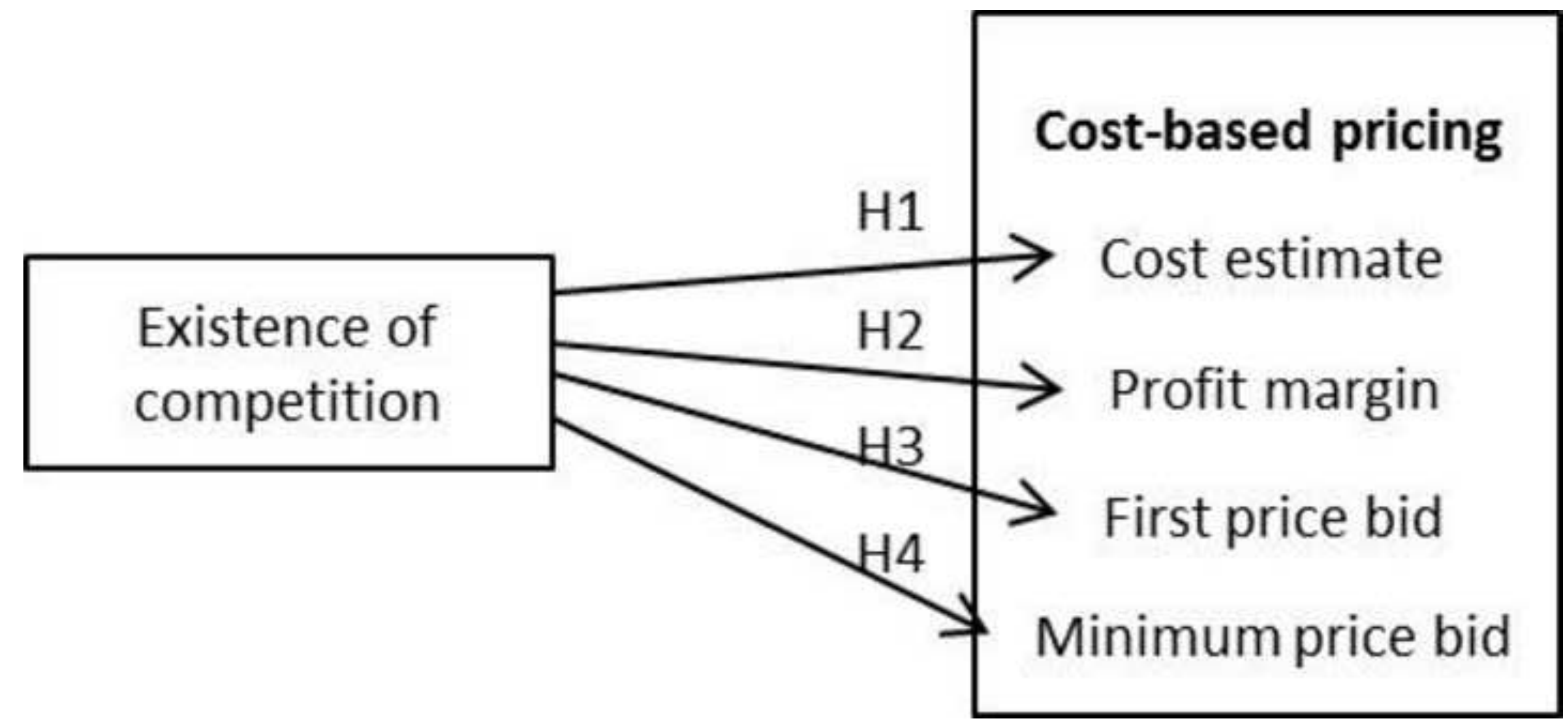




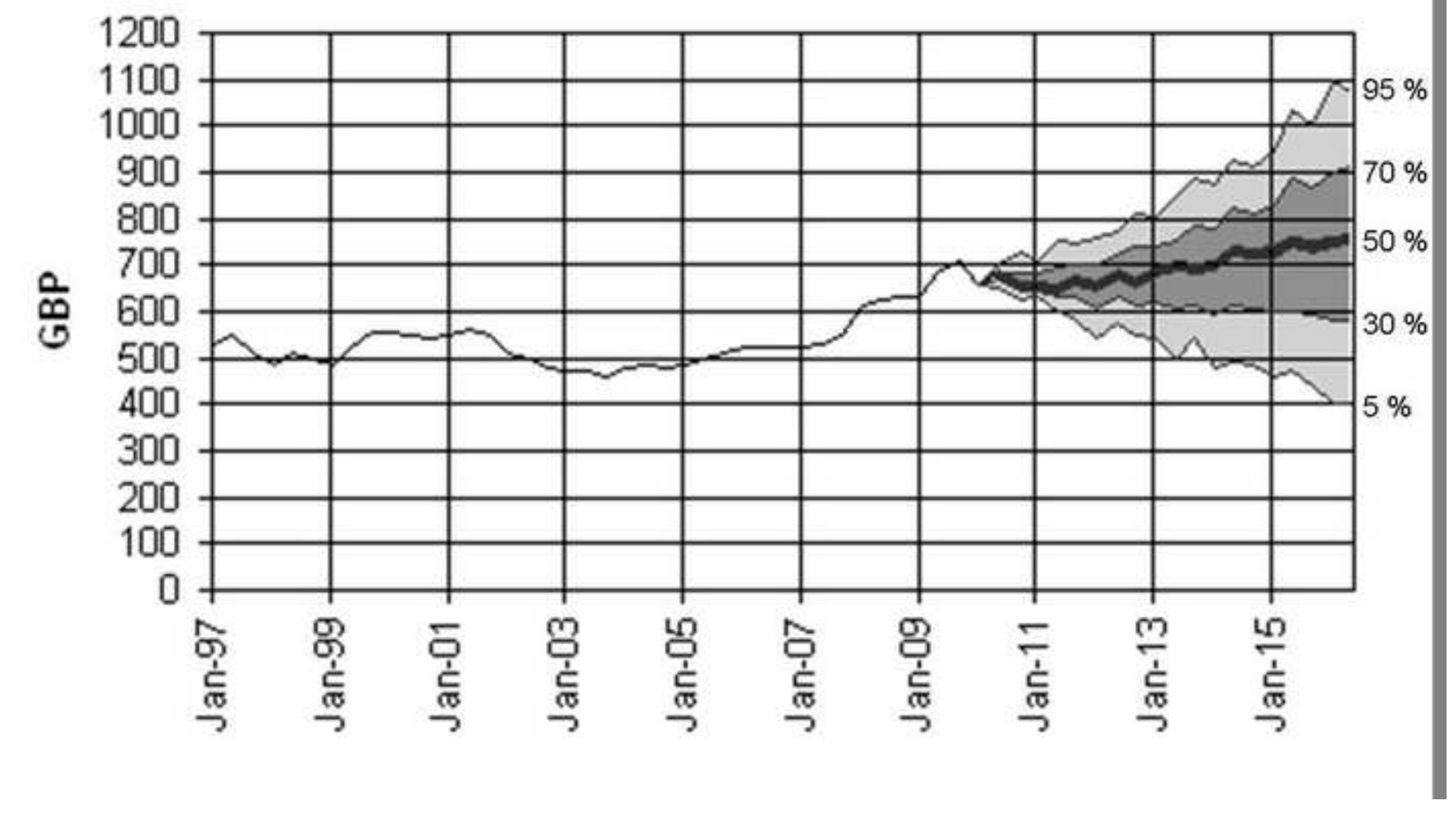

